\title{
Comparative analysis of gut microbial composition and potential functions in captive forest and alpine musk deer
}

\author{
Feng Jiang ${ }^{1,2,3} \cdot$ Pengfei Song ${ }^{1,2} \cdot$ Haijing Wang ${ }^{1,2,4} \cdot$ Jingjie Zhang ${ }^{1,2,3} \cdot$ Daoxin Liu ${ }^{1,2,4} \cdot$ Zhenyuan Cai $^{1,3}$.

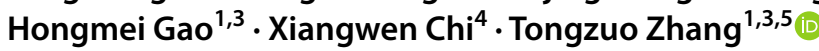

Received: 24 May 2021 / Revised: 28 December 2021 / Accepted: 9 January 2022 / Published online: 17 January 2022

(c) The Author(s) 2022

\begin{abstract}
Gut microbiota forms a unique microecosystem and performs various irreplaceable metabolic functions for ruminants. The gut microbiota is important for host health and provides new insight into endangered species conservation. Forest musk deer (FMD) and alpine musk deer (AMD) are typical small ruminants, globally endangered due to excessive hunting and habitat loss. Although nearly 60 years of captive musk deer breeding has reduced the hunting pressure in the wild, fatal gastrointestinal diseases restrict the growth of captive populations. In this study, $16 \mathrm{~S}$ rRNA high-throughput sequencing revealed the differences in gut microbiota between FMD and AMD based on 166 fecal samples. The alpha diversity was higher in FMD than in AMD, probably helping FMD adapt to different and wider habitats. The B-diversity was higher between adult FMD and AMD than juveniles and in winter than late spring. The phylum Firmicutes and the genera Christensenellaceae R7 group, Ruminococcus, Prevotellaceae UCG-004, and Monoglobus were significantly higher in abundance in FMD than in AMD. However, the phylum Bacteroidetes and genera Bacteroides, UCG-005, Rikenellaceae RC9 gut group, and Alistipes were significantly higher in AMD than FMD. The expression of metabolic functions was higher in AMD than in FMD, a beneficial pattern for AMD to maintain higher energy and substance metabolism. Captive AMD may be at higher risk of intestinal diseases than FMD, with higher relative abundances of most opportunistic pathogens and the expression of disease-related functions. These results provide valuable data for breeding healthy captive musk deer and assessing their adaptability in the wild.
\end{abstract}

\section{Key points}

- Alpha diversity of gut microbiota was higher in FMD than that in AMD

- Expression of metabolic and disease-related functions was higher in AMD than in FMD

Keywords Musk deer $\cdot$ Gut microbiota $\cdot$ Dominant bacteria $\cdot$ Metabolic functions $\cdot 16 \mathrm{~S}$ rRNA gene sequencing $\cdot$ Diseaserelated functions

Tongzuo Zhang
zhangtz@nwipb.cas.cn
Feng Jiang
fengjiangsf@yahoo.com
Pengfei Song
pfsong@nwipb.cas.cn
Haijing Wang
wanghj@ nwipb.cas.cn
Jingjie Zhang
jingjiezhang1@163.com
Daoxin Liu
liudx@nwipb.cas.cn
Zhenyuan Cai
caizhenyuan@nwipb.cas.cn
Hongmei Gao
gaohm@nwipb.cas.cn

Tongzuo Zhang

zhangtz@nwipb.cas.cn

Feng Jiang

fengjiangsf@yahoo.com

Pengfei Song

Haijing Wang

wanghj@nwipb.cas.cn

Jingjie Zhang

Daoxin Liu

Zhenyuan Cai

gaohm@nwipb.cas.cn
Xiangwen Chi

chixiangwen@163.com

1 Key Laboratory of Adaptation and Evolution of Plateau Biota, Northwest Institute of Plateau Biology, Chinese Academy of Sciences, Xining 810001, Qinghai, China

2 University of Chinese Academy of Sciences, Beijing 100049, China

3 Qinghai Provincial Key Laboratory of Animal Ecological Genomics, Xining 810001, Qinghai, China

4 Qinghai University, Xining 810016, Qinghai, China

5 Present Address: Northwest Institute of Plateau Biology, Chinese Academy of Sciences, Chengxi District, 23 Xinning Rd, XiningQinghai Province 810001, China 


\section{Introduction}

Gut microbiota and host evolve together, forming a complex microecosystem within the gastrointestinal tract of animals, which functions in material metabolism, nutrient absorption, immune regulation, resistance to pathogen invasion, and other host physiological processes (Nicholson et al. 2012). Gut microbiota is a complex and dynamically balanced ecological network, jointly maintaining the gut environment homeostasis and the health of the host (Hua et al. 2020). Imbalanced gut microbiota causes partial host dysfunction and significant changes in the host immune response, seriously affecting host health and growth (Gagniere et al. 2016). Recent studies have demonstrated that gut microbial structure abnormalities are associated with mental disorders, intestinal, metabolic, and other diseases (Dinleyici et al. 2018; Qin et al. 2012; Fung et al. 2017; Valles-Colomer et al. 2019). Moreover, various intrinsic and extrinsic factors such as host genetics (Fan et al. 2021), genetic background (Korach-Rechtman et al. 2019), diet (Wang et al. 2019), age (O'Toole et al. 2015; Guo et al. 2020a), seasonal change (Peddada 2017), and habitat environment (Barelli et al. 2020; Xiong et al. 2021) greatly affect gut microbial community structure.

In herbivorous mammals, gut microbiota secretes exogenous cellulases and hemicellulases that convert plant biomass into absorbable nutrients and energy (Naas et al. 2018). Ruminants possess a unique gastrointestinal microbiome and a specialized, compartmentalized digestive system consisting of the rumen, reticulum, omasum, and abomasum. The rumen is involved in microorganism fermentation, food digestion, material, and energy metabolism (Matthews et al. 2019; Prajapati et al. 2016). Food first enters the rumen of ruminants, where rumen microorganisms perform catabolism, and is further transferred into the reticulum for finer catabolism. Next, the omasum and abomasum degrade and convert the food into small molecules to provide energy and nutrients to the host (Enjalbert et al. 2017). The ruminant gut microbiota contains probiotics, opportunistic pathogens, and pathogens. The genera Bifidobacterium, Lactobacillus, and other beneficial anaerobes dominate the ruminant gastrointestinal tract (Xu et al. 2018). These genera are mutual symbionts with the host, and their metabolites inhibit the propagation of opportunistic pathogens and hinder gut colonization by opportunistic bacteria (Lepczynska and Dzika 2019; Zhao and Qing 2021). The opportunistic pathogens are mainly facultative, non-dominant aerobic bacteria of the intestine (Sassone-Corsi et al. 2016). Under conditions such as compromised host resistance or an imbalanced gut microbiota, these opportunistic bacteria rapidly multiply and cause disease in the host.
For musk deers, gastrointestinal diseases caused by opportunistic bacteria are the main factors limiting the expansion of musk deer artificial breeding (Zhao et al. 2011; Fan et al. 2018; Zhou et al. 2019). The forest musk deer (FMD, Moschus berezovskii) and alpine musk deer (AMD, Moschus chrysogaster) are two types of solitary small and threatened ruminants that inhabit forests and mountains of central and southwestern China. China harbors the most diverse musk deer resource, quantity, and yield (Sun et al. 2018). The musk secreted by the ventral gland of the male musk deer is traditional Chinese medicine and a highly priced natural fragrance with limited supply. The limited musk supply has caused excessive hunting and habitat fragmentation of the wild musk deer, whose population has decreased dramatically from approximately 3 million in the 1950 s to 31,800 in 2009 (Wu and Wang 2006; National Forestry and Grassland Administration 2009).

Both FMD and AMD are listed as endangered (EN) by the IUCN Red List and critically endangered (CR) by the Red List of Vertebrates in China (Wang and Harris 2015; Harris 2016; Jiang et al. 2016). In the late 1950s, China performed artificial FMD and AMD breeding, generating the largest captive population of musk deer species. This breeding relieved the resource pressure on wild populations and provided, to an extent, the traditional and natural musk resources (Huang et al. 2013; Fan et al. 2019). Artificial breeding of musk deer can also reintroduce provenance. For example, in 2017, 13 artificially bred FMD were released, for the first time, into the wild in Shaanxi Province, China (National Forestry and Grassland Administration 2017). The release was an important step in conserving endangered species, recovering, and expanding wild populations. However, captive musk deer are more susceptible to dysbiosis-caused intestinal diseases with higher incidence and mortality rates than wild musk (Li et al. 2018). Therefore, studying captive FMD and AMD gut microbiota is beneficial for evaluating their current artificial rearing conditions and understanding the appropriate capacity of gut microbial changes for future musk breeding. However, the differences in gut microbial composition and function between different ages of FMD and AMD in different seasons are still lacking.

In this study, 16S rRNA gene sequencing estimated FMD and AMD gut microbiota composition and diversity under different taxonomic levels. The aim was to explore (i) the difference between gut microbiota diversity between captive FMD and AMD, (ii) the difference between dominant gut bacteria and opportunistic pathogens in and between the two species, and (iii) the differences of potential metabolic and disease-related functions between the two species. This study comprehensively and systematically investigated the differences in gut microbial composition and potential function between FMD and AMD in different seasons and ages, 
providing a scientific basis for effective health management of captive musk deer.

\section{Materials and methods}

\section{Sampled materials}

A total of 107 fresh feces samples from captive FMD (57 samples in late spring and 50 samples in winter) and 59 samples from captive AMD ( 35 samples in late spring and 24 samples in winter) were collected by the noninvasive sampling method in this study. The FMD farm is located in the remote gully of A'rou Township, Qilian County, Qinghai Province $\left(100^{\circ} 21^{\prime}\right.$ E, $38^{\circ} 7^{\prime}$ N) (Fig. 1a), with an altitude of 3,002 $\mathrm{m}$. The annual mean temperature and annual precipitation are $-0.1{ }^{\circ} \mathrm{C}$ and $403 \mathrm{~mm}$, respectively. The AMD farm is located in the Xinglong Mountain National Nature Reserve in Yuzhong County, Gansu Province (104 ${ }^{\circ} 4^{\prime} \mathrm{E}$, $35^{\circ} 49^{\prime} \mathrm{N}$ ), with an altitude of $2,171 \mathrm{~m}$. The annual mean temperature and annual precipitation are $5.4{ }^{\circ} \mathrm{C}$ and $406 \mathrm{~mm}$, respectively.

Before sampling, the individual enclosures of FMD and AMD were cleaned, and the individuals were kept in separate enclosures so that the fresh fecal samples could be collected from each individual the following morning. During the sampling process, fecal samples were collected shortly after a musk deer was observed defecating with sterile disposable polyethylene gloves and put into sterile bags. After labeling, all samples were temporarily stored in the vehicle-mounted refrigerator $\left(-20^{\circ} \mathrm{C}\right)$ and later transferred into the $-80{ }^{\circ} \mathrm{C}$ ultra-low temperature refrigerator in the laboratory for later DNA extraction.

\section{DNA extraction and 16S rRNA gene sequencing}

After pretreatment of fecal samples, total bacterial DNA was extracted using an E.Z.N.A. ${ }^{\circledR}$ soil DNA kit (Omega Biotek, Norcross, GA, USA) according to the manufacturer's instructions, and subsequently stored at $-20{ }^{\circ} \mathrm{C}$ for further analysis. The quality of DNA extraction was determined by $1 \%$ agarose gel electrophoresis, and the concentration and purity of DNA in each sample were determined by NanoDrop2000 instrument (Thermo Fisher Scientific, Waltham, MA, USA).

The extracted total bacterial DNA was used as the template and universal bacteria primers $515 \mathrm{~F}\left(5^{\prime}\right.$-GTGCCA GCMGCCGCGG-3') and 907R (5'-CCGTCAATTCMTTTRAGTTT-3') were subjected to amplify the V4-V5 region of the bacterial 16S rRNA genes. PCR reactions for
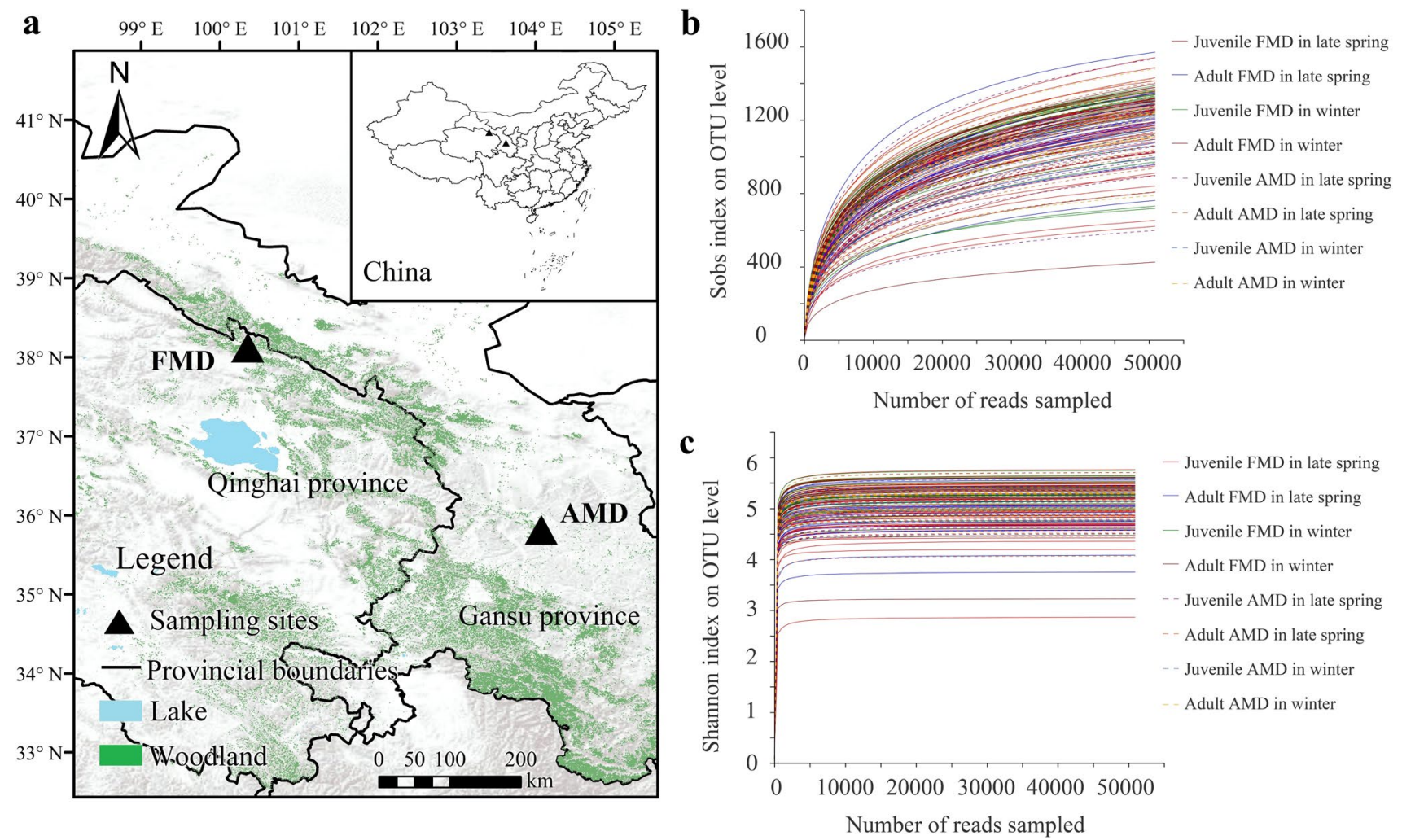

Fig. 1 Diagram of sample collection of musk deer (a). Rarefaction curves of the 16S rRNA gene reads based on OTUs with $S_{\text {obs }}$ index (b) and Shannon index (c) 
each sample were carried out in triplicate $20-\mu \mathrm{L}$ reactions with $4 \mu \mathrm{L}$ TransStart FastPfu buffer $(5 \times), 2 \mu \mathrm{L}$ dNTP mix (2.5 mM), $0.8 \mu \mathrm{L}$ of each primer $(5 \mu \mathrm{M}), 0.4 \mu \mathrm{L}$ TransStart FastPfu DNA polymerase, $10 \mathrm{ng}$ sample DNA, and certified DNA-free PCR water up to $20 \mu \mathrm{L}$. PCR amplifications were performed on an ABI GeneAmp 9700 PCR system (Applied Biosystems, Foster City, CA, USA) according to the following procedures: $98{ }^{\circ} \mathrm{C}$ for $3 \mathrm{~min}$ (initial denaturing), 27 cycles of $95^{\circ} \mathrm{C}$ for $30 \mathrm{~s}$ (denaturing), $55^{\circ} \mathrm{C}$ for $30 \mathrm{~s}$ (annealing), $72{ }^{\circ} \mathrm{C}$ for $45 \mathrm{~s}$ (extension), and $72{ }^{\circ} \mathrm{C}$ for $10 \mathrm{~min}$ (final extension).

Replicated amplicons were pooled and visualized by electrophoresis in $2.0 \%$ agarose gel, and purified using AxyPrep DNA Gel Extraction Kit (Axygen Biosciences, Union City, CA, USA) according to manufacturer's instructions. Subsequently, the purified amplicons were quantified by Quantus ${ }^{\text {TM }}$ Fluorometer (Promega, Madison, WI, USA) and were pooled in equimolar amounts. The DNA library was prepared using the NEXTflex ${ }^{\circledR}$ Rapid DNA-Seq Kit (Bioo Scientific, Austin, TX, USA) and sequenced on the Illumina MiSeq PE300 platform (Illumina, San Diego, CA, USA) at the Shanghai Majorbio Bio-Pharm Technology Co., Ltd., Shanghai, China.

\section{Operational taxonomic units (OTUs) clustering and taxonomic annotation}

The raw sequencing data generated from Illumina MiSeq were pre-processed using Trimmomatic (version 0.39) to remove the known adaptor, specific primers, and low-quality ends (Bolger et al. 2014). We filtered bases with the average quality score below 20 in the tail of reads and set a sliding window of $50 \mathrm{bp}$. If the average quality score in the window was lower than 20, the back-end base was truncated from the window, the reads below $50 \mathrm{bp}$ after quality control were filtered, and the reads containing ambiguous base were removed. According to overlap relationship between paired-end (PE) reads, paired reads were merged into a sequence with the minimum overlap length of $10 \mathrm{bp}$ using FLASH (version 1.2.7) (Magoč and Salzberg 2011). The overlap region allowed a maximum mismatch ratio of 0.2 , and sequences with no matches were discarded.

UPARSE software (version 7.1, http://drive5.com/ uparse/) was used to cluster OTUs with $97 \%$ similarity cutoff, and chimeras were identified and removed during the clustering process (Costello et al. 2009). The sequence with the highest frequency in each OTU was selected as the representative sequence for further annotation in the process of assigning OTUs. Species classification was annotated for each sequence using ribosomal database project (RDP) classifier (http://rdp.cme.msu.edu/) (Wang et al. 2007), and the comparison threshold was set to $80 \%$ in the Silva database (Silva 138/16S) (Li et al. 2017). Based on the taxonomy assignment, all features that refer either to mitochondria, chloroplasts, or archaea were filtered, and the results were aligned to generate the final bacterial OTU table.

\section{Bioinformatic analysis}

The OTUs were annotated for species taxonomy, and the corresponding abundance information of each OTU annotation results in each sample was counted. Before the subsequent analysis, the normalized bacterial OTU table was generated by subsampling randomly based on the minimum number of sample sequences. Community bar charts and Venn charts were used to plot the abundance of each group of FMD and AMD using "stats" package of R software (version 3.3.1, https://www.r-project.org/) (Ji et al. 2017), and the unique bacteria phylum and genus were counted.

Similarities and differences among the microbial communities between FMD and AMD were estimated using cluster heatmap analysis with the $\mathrm{R}$ software (packages "pheatmap") (Perry 2016). Alpha diversity can reflect the diversity of gut microbial composition. At the OTU level, the observed richness $\left(S_{\text {obs }}\right)$ index and Shannon index were calculated to measure the diversity of gut microbial composition with Qiime software (http://qiime.org/scripts/assign taxonomy) (Caporaso et al. 2010). Then the Wilcoxon ranksum test was used to analyze the significant differences of the alpha diversity index among different groups with the $\mathrm{R}$ software (packages "stats").

Comparative analysis of species diversity in community composition was conducted to explore the similarity or difference of community composition between different groups. Beta diversity analysis between different groups was performed with principle coordinates analysis (PCoA) based on Bray-Curtis distances using the R software (packages "vegan"). Analysis of similarities (ANOSIM), a non-parametric statistical test, was used to test the differences in relative abundance of dominant bacteria and opportunistic pathogens with a two-tailed test with the R software (packages "vegan," anosim function) (Oksanen et al. 2019). The false discovery rate (FDR) was selected for multiple checks and corrections of $P$ value with confidence interval of 0.95 .

The metabolic functions and disease-related functions of bacterial communities were predicted using phylogenetic investigation of communities by reconstruction of unobserved states (PICRUSt) software (Langille et al. 2013). Genome sequence data were compared with the Kyoto encyclopedia of genes and genomes (KEGG) database and the nonsupervised orthologous groups (EggNOG) database was used to complete gene functional annotation and classification analysis (Cao et al. 2020). The Wilcoxon rank-sum test was used to analyze the significant difference in functional abundance between different groups. 


\section{Results}

\section{Assessment of sequence data}

After strict filtering and quality control of the raw reads, 22,892,300 high-quality clean reads (average 137,905 reads/sample) of FMD and AMD were obtained, generating an average reading length of $375 \mathrm{bp}$. The rarefaction curves of the $S_{\mathrm{obs}}$ and Shannon indexes smoothened with increased sequencing quantity (Fig. 1b, c), and Good's coverage values were higher than $99 \%$. Thus, the sequencing quantity reached saturation, and the data quality was reliable. Therefore, the sequencing data comprehensively reflected the gut microbial information in FMD and AMD under different seasons and ages.

A 97\% similarity clustering identified 3,213 effective OTUs of FMD and AMD, and the effective sequences were extracted and screened based on the minimum sample. The OTUs were classified into 20 phyla, 33 classes, 83 orders, 154 families, and 375 genera.

\section{Gut microbial composition of FMD and AMD}

Firmicutes and Bacteroidetes were the dominant bacterial phyla across seasons and ages, followed by Proteobacteria and Actinobacteria in musk deer (Fig. 2a).

The cluster heatmap of the top 50 relative abundances showed that the genera Bacteroides, UCG-005, Christensenellaceae $R 7$ group, Rikenellaceae RC9 gut group, Alistipes, Ruminococcus, Prevotellaceae UCG 004, and Monoglobus were dominant in both FMD and AMD across seasons and ages (Fig. 2b). However, the genus NK4A214 group was dominant in FMD, while Anaerostipes and Candidatus Stoquefichus were dominant in AMD. The listed dominant genera belong to the phyla Firmicutes and Bacteroides. Additionally, all the FMD and AMD bacterial genera clustered into one group. In late spring, FMD and AMD shared 18 bacterial phyla and 259 bacterial genera, while in winter, FMD and AMD shared 13 bacterial phyla and 215 bacterial genera (Fig. 2c).

\section{Difference analysis of gut microbiota between FMD and AMD}

The $S_{\text {obs }}$ and Shannon indexes reflected the richness and diversity of gut microbiota in captive FMD and AMD. The FMD $\alpha$-diversity was higher than AMD across seasons and ages, but the difference was insignificant (Fig. 2d).

The Bray-Curtis distance algorithm determined the distance between samples, and ANOSIM analysis tested the inter-group and intra-group differences between FMD and AMD.

PCoA showed that all the $R$ values were $>0(P=0.001)$, indicating significant differences in the gut microbial composition of FMD and AMD in different seasons and ages. The inter-group differences were significantly greater than the intra-group differences (Fig. 2e, f). Adult FMD and AMD had higher $\beta$-diversity than juveniles, and the value was higher in winter than in late spring (Fig. $2 \mathrm{~g}$ ).

\section{Analysis of dominant bacteria differences between FMD and AMD}

The Wilcoxon rank-sum test showed that the phyla Firmicutes and Bacteroidetes differed significantly between FMD and AMD (Fig. 3a). The relative abundance of the phylum Firmicutes in FMD was significantly higher than AMD $(P<0.05)$, while the phylum Bacteroidetes showed on the contrary a higher relative abundance in AMD than FMD. However, the relative abundance of Proteobacteria was lower in FMD than AMD during late spring but higher than AMD in winter, with no significant differences (Fig. 3b). In winter, Actinobacteria was significantly higher in FMD than in AMD.

At the genus level, the relative abundances of genera Christensenellaceae $R 7$ group, Ruminococcus, Prevotellaceae UCG-004, Monoglobus, and NK4A214 group were significantly higher in abundance in FMD than in AMD. In contrast, the genera Bacteroides, UCG-005, Rikenellaceae RC9 gut group, Alistipes, and Candidatus Stoquefichus were significantly higher in abundance in AMD than in FMD.

\section{Metabolic function difference analysis}

Functional enrichment analysis using the KEGG database identified metabolic function as primary function for gut microbial genes in FMD and AMD. The enriched pathways include carbohydrate metabolism (9.62\%), amino acid metabolism (7.19\%), energy metabolism (4.27\%), metabolism of cofactors and vitamins $(4.22 \%)$, nucleotide metabolism ( $2.81 \%)$, lipid metabolism (1.80\%), glycan biosynthesis and metabolism (1.67\%), biosynthesis of other secondary metabolites (1.66\%), metabolism of other amino acids (1.18\%), and metabolism of terpenoids and polyketides (0.97\%).

At level 1, the metabolic function was significantly enriched in AMD (with stronger enrichment in juvenile than in adult musk deer) than in FMD (Fig. 4a). At level 2, ten metabolic functions were more enriched in AMD than in FMD (Fig. 4b). The difference between juvenile FMD and AMD was higher than between adults.

Additional functional annotation using the EggNOG database also identified metabolic function as the primary 
a

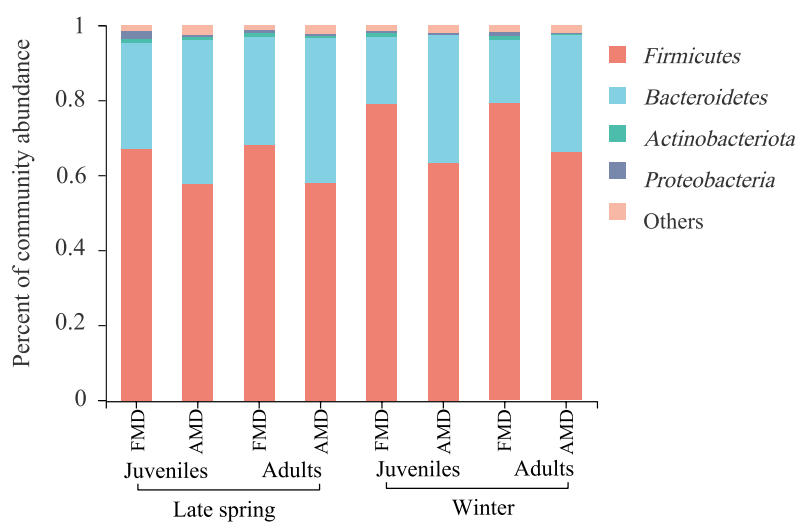

c

FMD adults AMD juveniles

$(19,319,19,293)$

$(19,317,15,262)$

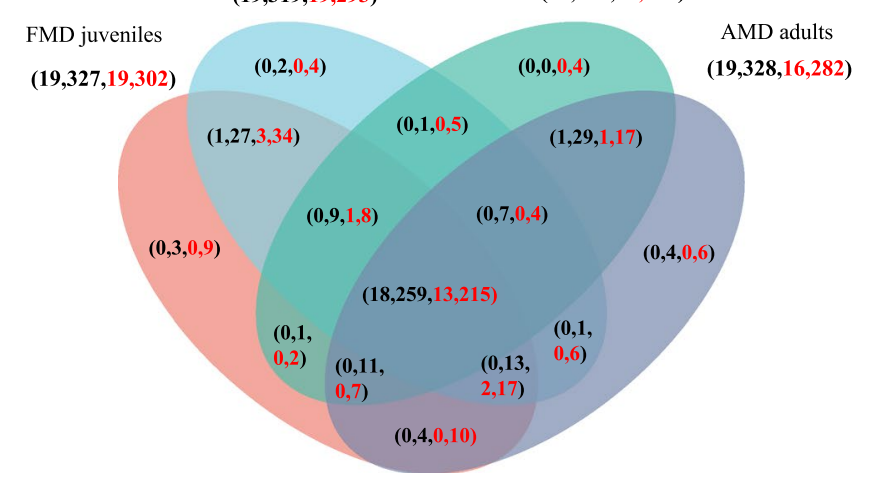

d

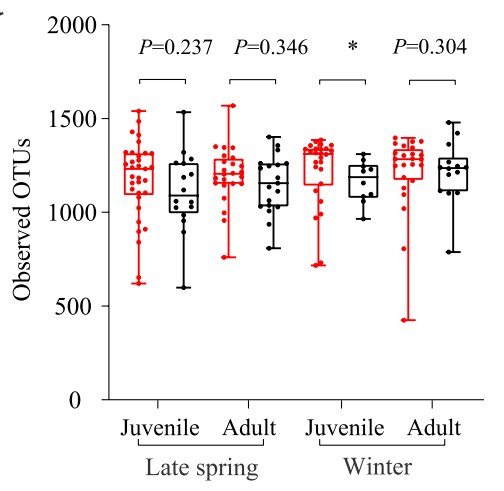

e

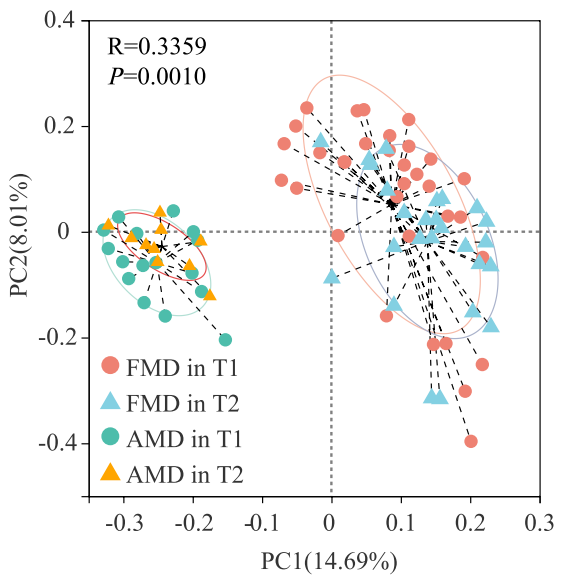

b

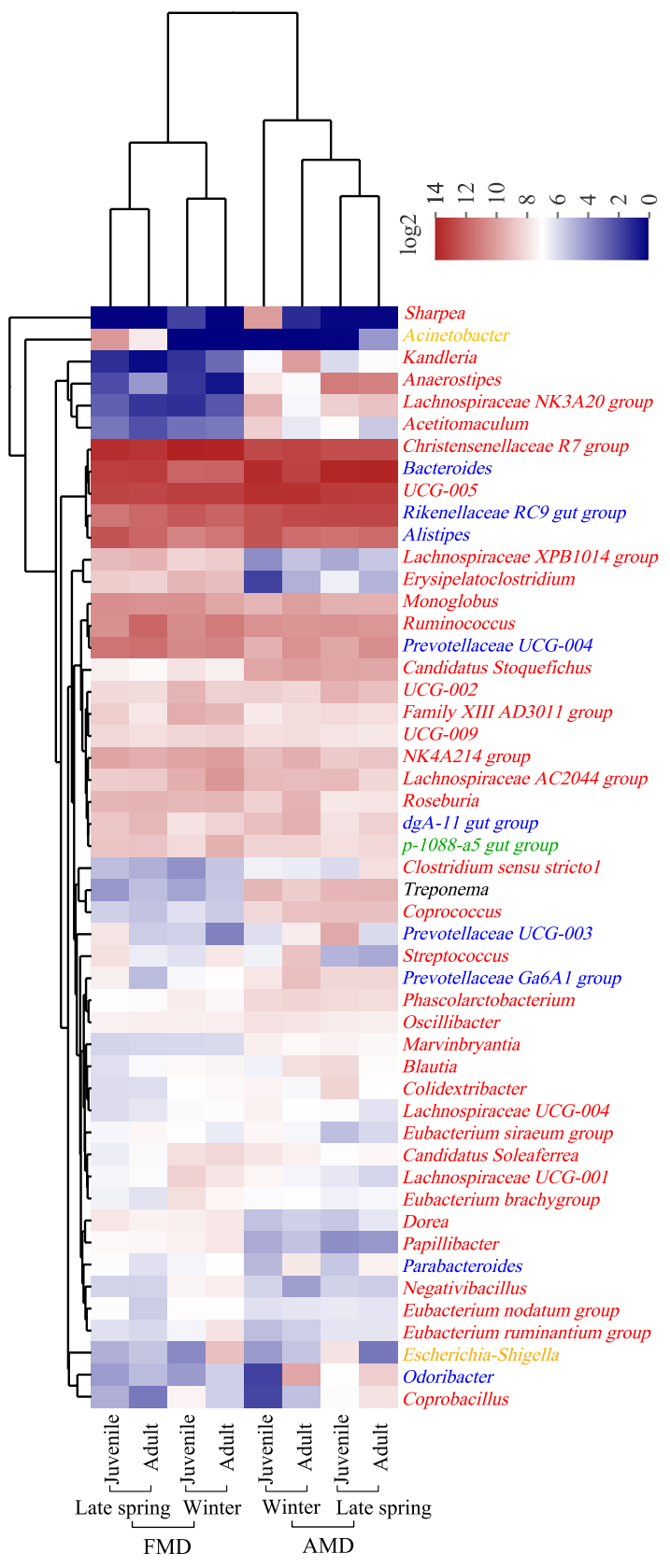

f

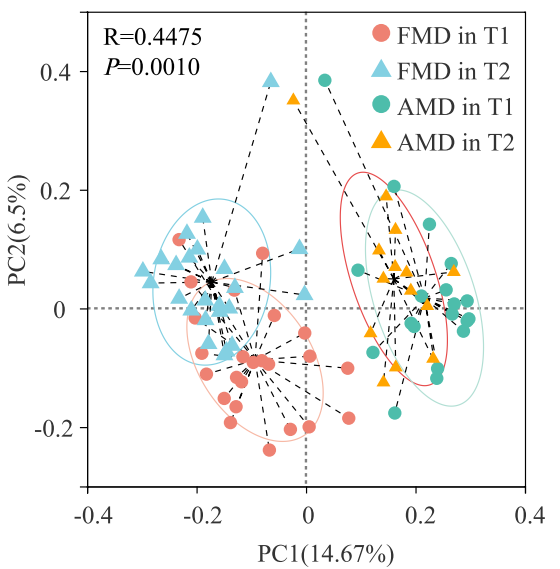

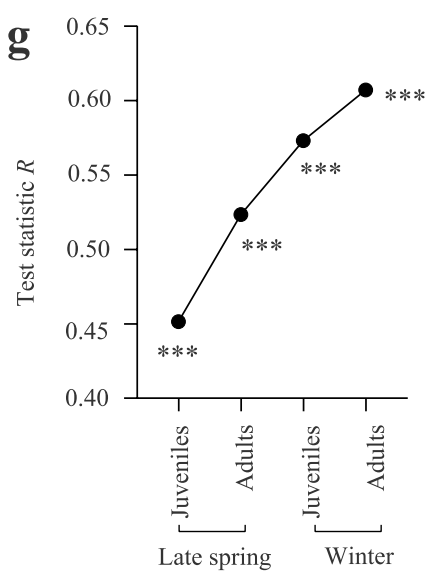


4Fig. 2 Difference analysis of gut microbiota between FMD and AMD. a Histogram of relative abundance of individual bacterial phyla of musk deer. b Cluster heatmap analysis based on identifiable bacterial genera with relative abundance of top 50 for musk deer. The red, blue, orange, green, and black letters represented the phyla Firmicutes, Bacteroidetes, Proteobacteria, Planctomycetes, and Spirochaetes, respectively. c Analysis of core and unique bacteria of musk deer at phylum (the left number) and genus (the right number) levels by Venn plots. The black and red numbers represented late spring and winter, respectively. d Seasonal variation of $\alpha$-diversity in gut microbiota of musk deer based on $S_{\mathrm{obs}}$ and Shannon indexes. PCoA analysis of gut microbial composition between juvenile (e) and adult (f) FMD and AMD. g ANOSIM analysis of gut microbiota between FMD and AMD in the same age and seasons. $* P<0.05$ (Wilcoxon rank-sum test), $* * P<0.01$, and $* * * P<0.001$. ns, not significant

function, especially energy production and conversion $(6.13 \%)$, carbohydrate $(6.59 \%)$, amino acid $(9.85 \%)$, nucleotide $(3.82 \%)$, coenzyme $(4.18 \%)$, lipid $(2.60 \%)$, and inorganic ion transport and metabolism (5.73\%), respectively. The listed functions were more enriched in AMD (significantly higher in juvenile than adults) than in FMD (Fig. 4c).

The KEGG database showed that gut microbiota with disease-related functions was significantly enriched in AMD than in FMD (Fig. 5e). The difference between juvenile FMD and AMD was higher than between adult musk deer.

\section{Differences analysis of opportunistic pathogens and disease-related functions}

The relative abundance of opportunistic pathogens was less than $0.1 \%$ in both FMD and AMD (Fig. 5). In late spring, the relative abundance of the genera Erysipelatoclostridium and Parasutterella was significantly higher in abundance in juvenile FMD than in juvenile AMD. However, the genera Treponema, Oscillibacter, Corynebacterium, Clostridium sensu stricto 1, Clostridium sensu stricto 6, and Aerococcus were significantly higher in abundance in juvenile AMD than in juvenile FMD (Fig. 5a). The genus Erysipelatoclostridium was significantly higher in abundance adult FMD than in adult AMD. In contrast, the genera Treponema, Odoribacter, Clostridium sensu stricto 1, Corynebacterium, Parasutterella, and Clostridium sensu stricto 6 were significantly higher in abundance in adult AMD than in adult FMD (Fig. 5b).

During winter, the relative abundance of the genera Erysipelatoclostridium, Anaeroplasma, and Actinomyces was significantly higher in juvenile FMD than in juvenile AMD. On the contrary, the genera Treponema, Clostridium sensu stricto 1, Escherichia-Shigella, Parasutterella, Clostridium sensu stricto 6, and Aerococcus were significantly higher in abundance in juvenile AMD than in juvenile FMD (Fig. 5c). The genera Erysipelatoclostridium, Escherichia-Shigella, Corynebacterium, Actinomyces, and Aerococcus were significantly higher in abundance in adult FMD than in adult
AMD in winter. However, the genera Odoribacter, Streptococcus, Treponema, Clostridium sensu stricto 6, Parasutterella, and Bacillus had a significantly higher relative abundance in adult AMD than in adult FMD (Fig. 5d).

\section{Discussion}

The 16S rRNA high-throughput sequencing technology is widely applied to study gut microbial structure and diversity of various endangered wildlife (Antwis et al. 2019; Wei et al. 2019; Guo et al. 2020b). Endangered animals are generally hard to obtain because of their small population size, but their fecal samples are easier to collect without harming animals. Additionally, fecal samples represent the composition and function of microorganisms in the gut microbiota of hosts (Aguirre et al. 2015; Rounge et al. 2018). Collecting fecal samples from endangered wildlife through noninvasive means has become the best research method for conservation biology (Knutie and Gotanda 2018; Ning et al. 2020). Moreover, both artificial breeding and ex situ conservation are effective for maintaining and restoring endangered wildlife populations (Thitaram and Brown 2018; Wang et al. 2016; Willard et al. 1996). Artificial breeding relieves the hunting pressure on wild populations and provides valuable medicinal or raw materials while releasing captive, trained individuals into the wild (Comizzoli and Holt 2019; Silla and Byrne 2019). Thus, this approach is proven and important for conserving rare and endangered species. Varied feeding environments cause diversity and community differences in gut microbiota between captive and wild individuals. For example, gut microbial diversity, metabolic pathways, and cellulose-degrading enzyme activities decreased in captive compared to wild individuals. However, antibiotic resistance genes, heavy metal tolerance genes, the abundance of potential pathogens, and the risk of disease increased in captive compared to wild individuals (Wasimuddin et al. 2017; Chi et al. 2019; Gao et al. 2019). In this study, fecal FMD and AMD samples were obtained by noninvasive means. A $16 \mathrm{~S}$ rRNA high-throughput sequencing determined the diversity and functional differences of gut microbiota between musk deer. Animal age and sex were controlled, and gut microbiota of captive FMD and AMD was analyzed and compared.

Various factors affect the gut microbiota, including food, the most important source of energy and nutrition for both host and gut microbiota (Wu et al. 2011). The co-evolution of gut microbiota and host, the host genotype (Macke et al. 2017), and genetic polymorphism shape gut microbiota, thus, influencing host susceptibility to disease (Kovacs et al. 2011; De Filippo et al. 2010). Nevertheless, the composition and function of gut microbiota vary in different stages of the host life cycle, increasing in diversity and stability from birth to adult stages while decreasing from adult to old 

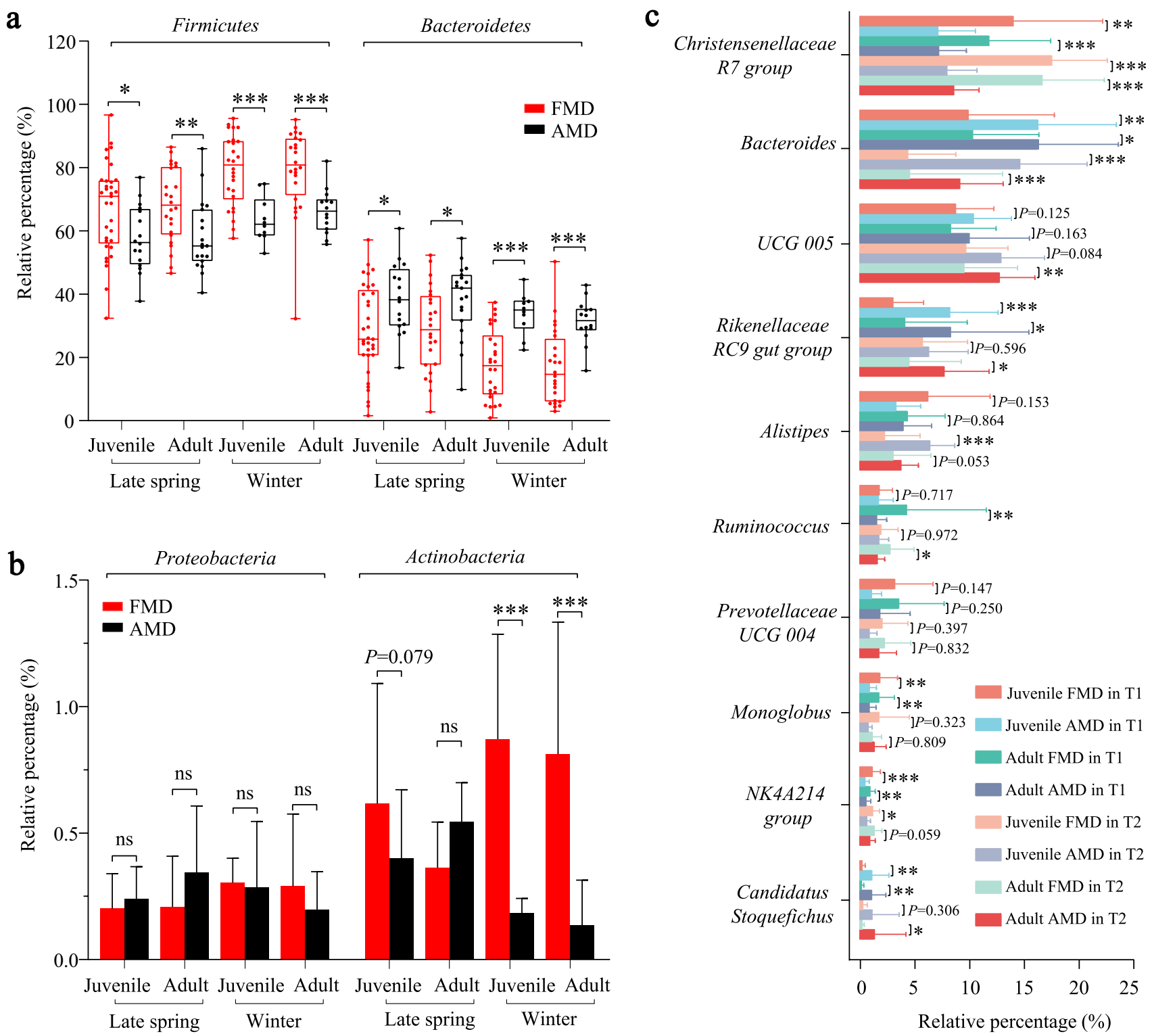

Fig. 3 Difference analysis of dominant bacteria between FMD and AMD. a Differential analysis of Firmicutes and Bacteroidetes between FMD and AMD. b Differential analysis of Proteobacteria and Actinobacteria between FMD and AMD. c Differential analysis

stages (O'Toole and Jeffery 2015). Male and female hosts have different feeding structures, food availability, immunity, metabolite control, and hormone secretion, causing differences in the diversity and function of gut microbiota (Fransen et al. 2017; Johnson et al. 2020). Besides, seasonal variation changes food resources, habitat environment, developmental stage, and migration behavior, possibly all changing host gut microbiota (Baniel et al. 2021; Tong et al. 2020; Shor et al. 2020).

Alpha diversity is the quantitative indicator of host gut microbial diversity, stability, and composition, and is an important evidence of the host health status (Shanahan of dominant bacterial genera between FMD and AMD. $* P<0.05$ (Wilcoxon rank-sum test), ${ }^{* *} P<0.01$, and $* * * P<0.001$. ns, not significant

2010). Higher alpha diversity indicates a complex and stable gut microbiota, less affected by food variation, and more resistant to external disturbances. Thus, higher alpha diversity is more conducive to host health because hosts can adapt and regulate their homeostasis (Ley et al. 2006; Lang et al. 2018). This study showed that captive FMD had a higher alpha diversity than captive AMD of the same age and season, consistent with previous studies (Hu et al. 2017). FMD and AMD are different musk deer species. Hence, the gut microbial diversity from this study is inadequate for comparing the health status of both species under a captive environment. However, 

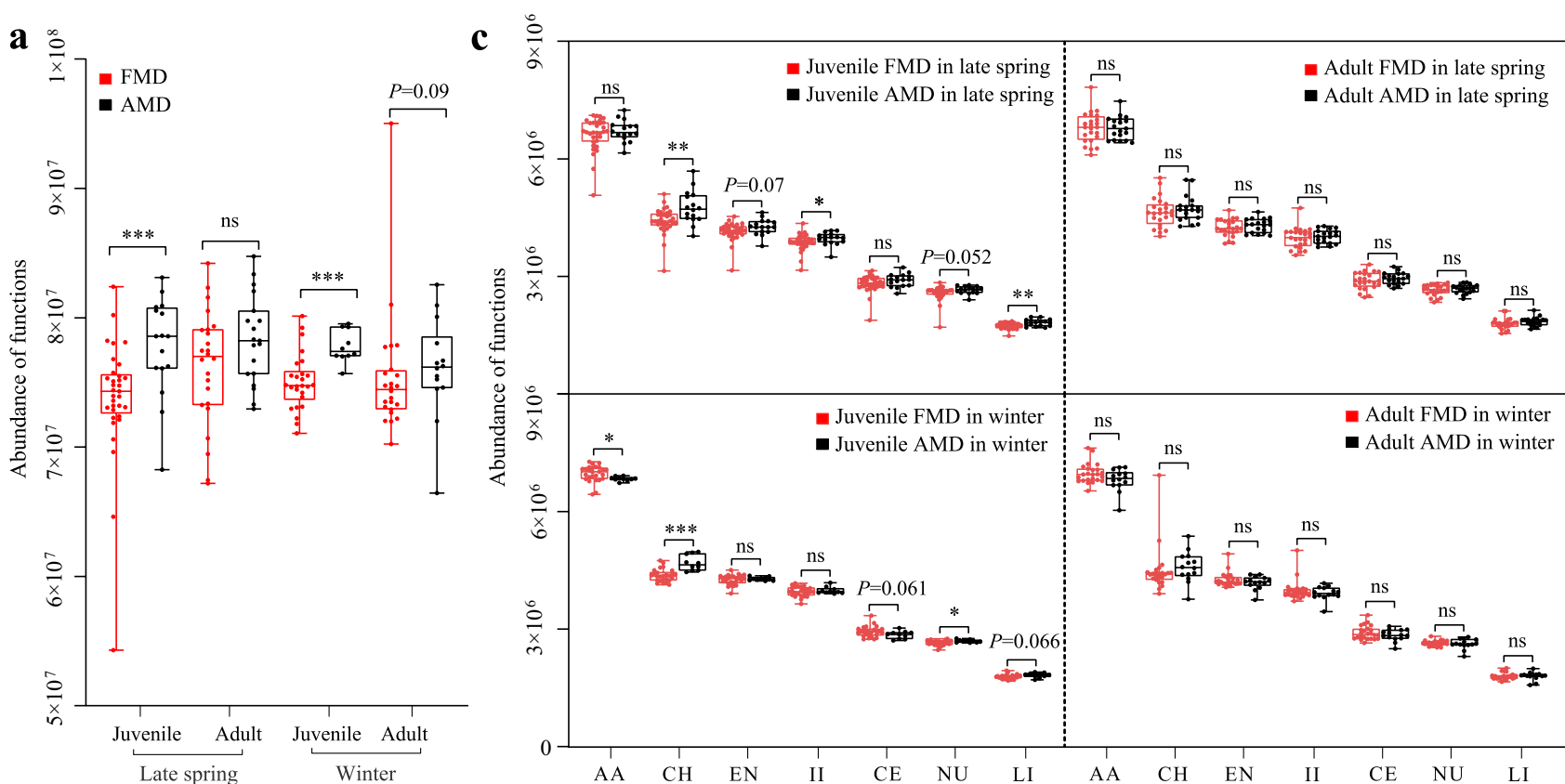

b

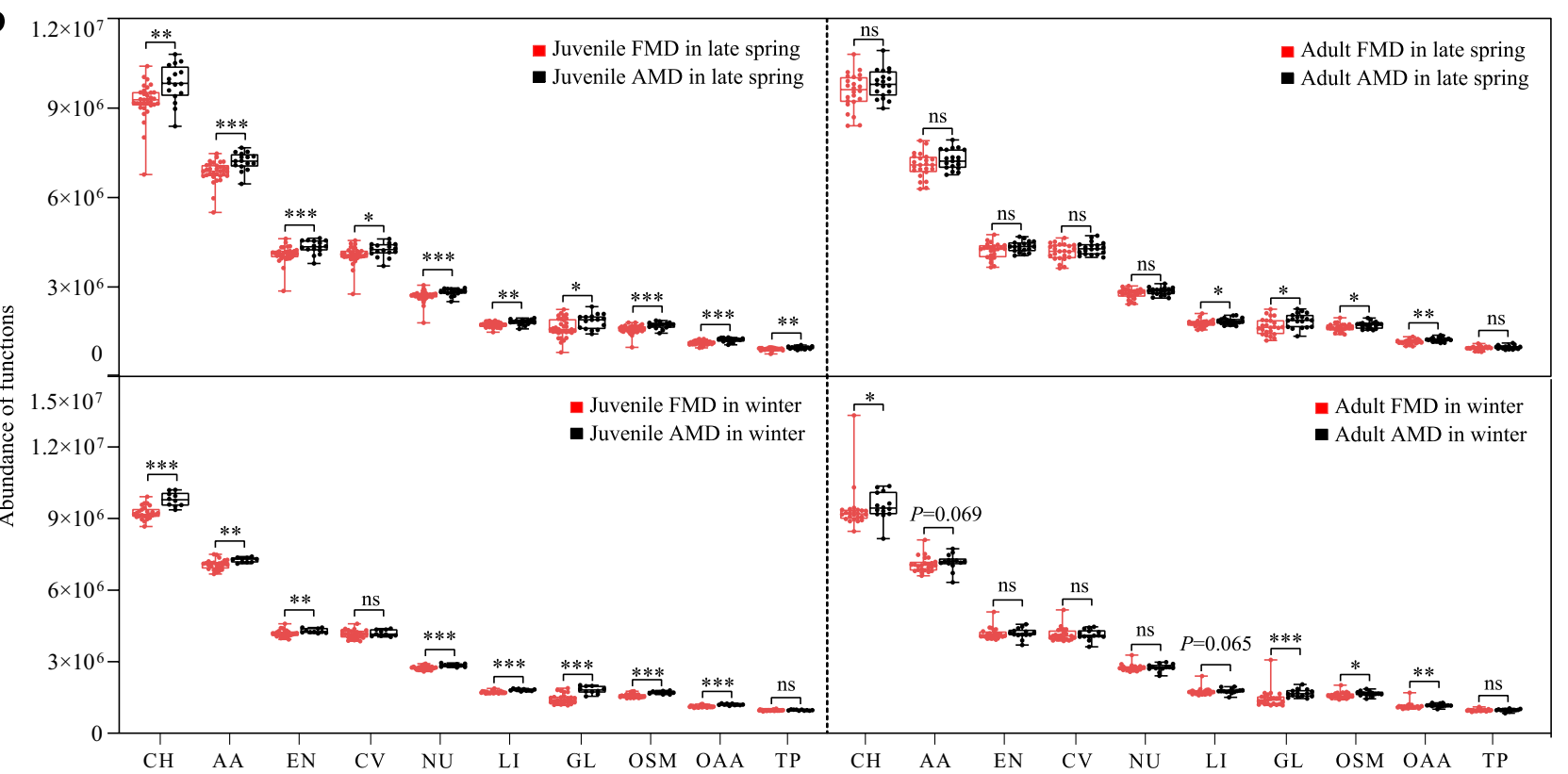

Fig. 4 Difference analysis of metabolic function between FMD and AMD based on the KEGG database at level 1 (a), at level 2 (b), and the EggNOG database (c)

previous studies showed that FMD has a larger suitable habitat than AMD (Jiang et al. 2020). FMD is the most widely distributed deer species with the highest population in China, followed by AMD (National Forestry and Grassland Administration 2009). Musk deer breeding in captivity has taken over 60 years since the 1960s, but different studies hypothesize a higher alpha diversity in wild FMD than in wild AMD (Li et al. 2017). Therefore, higher alpha diversity of gut microbiota probably benefits FMD adaption to different habitats.
Gut microbiota is rich in genes for the metabolism of carbohydrates, amino acids, fats, cellulose, short-chain fatty acids (SCFAs), bile acids, and the synthesis of methane and vitamins (Sasaki et al. 2019). These genes synthesize enzymes and regulate biochemical metabolic pathways necessary for metabolizing various substances for host sustenance (Tremaroli and Backhed 2012). Host metabolism is closely related to the growth and development of the host. As hosts age, the gut microecosystem gradually forms complex digestive and metabolic functions. The diversity and 

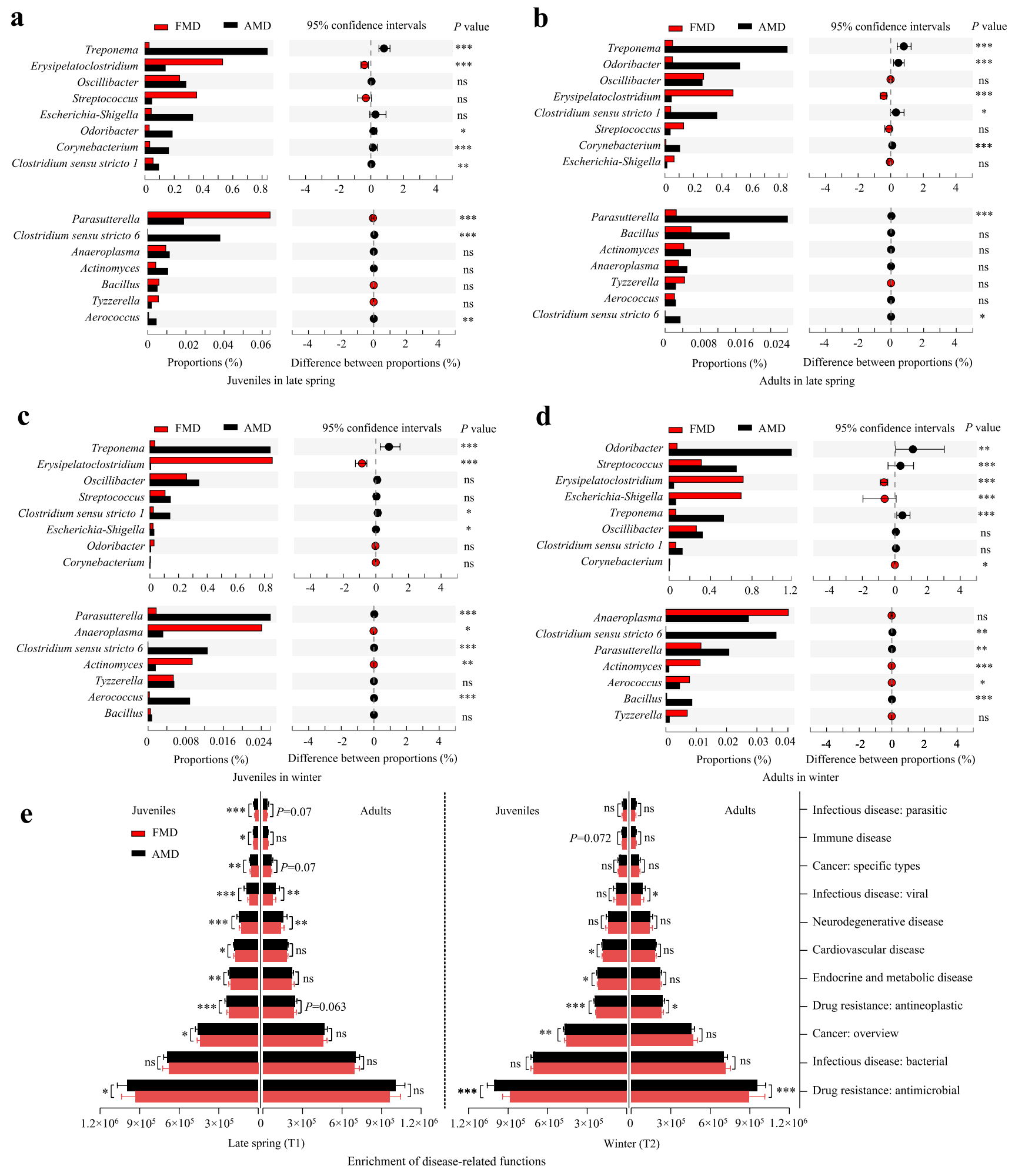

Fig. 5 Differences analysis of opportunistic pathogens between FMD and AMD for juveniles in late spring (a) and winter (c), and for adults in late spring (b) and winter (d). e Differences analysis of disease-related functions between FMD and AMD

stability of the gut microecosystem ensure normal metabolic function, nutrient digestion, and absorption by the host. However, imbalanced microbiota significantly alters the host metabolic and physiological processes, causing host susceptibility to diseases, especially metabolic disease (Torres-Fuentes et al. 2017). 
Dominant bacteria are key in metabolic function. This study showed that the phyla Firmicutes and Bacteroidetes were dominant, accounting for $>90 \%$ diversity in musk deer species across different seasons and ages. The above results are consistent with other results on the gut microbial composition in FMD, AMD, and other ruminants (Hu et al. 2017; Zhao et al. 2019a, b; Fountain-Jones et al. 2020). In ruminants, the phylum Firmicutes promotes fiber and cellulose degradation into volatile fatty acids, thus, facilitating food digestion, animal growth, and development (Wang et al. 2018). In this study, the relative abundance of Firmicutes was significantly higher in FMD than in AMD, while Bacteroidetes was significantly higher in abundance in FMD than in AMD. The genera Bacteroides, UCG-005, Christensenellaceae $R 7$ group, Rikenellaceae RC9 gut group, Alistipes, Ruminococcus, Prevotellaceae UCG 004, and Monoglobus were dominant in both FMD and AMD. Among these, the genera Christensenellaceae $R 7$ group, Ruminococcus, and Prevotellaceae UCG 004 belong to Firmicutes. Studies have shown that the genus Ruminococcus produces numerous cellulase and hemicellulase enzymes through fermentation in the rumen of ruminants (Matulova et al. 2008; La Reau et al. 2016). These enzymes convert the dietary fiber in food into various nutrients needed by the host, and play a key role in food digestion and carbohydrate metabolism (La Reau and Suen 2018). The genus Christensenellaceae R7 group, also abundant in the rumen of ruminants, is very important to the structure and function of the host intestinal tract and is mainly involved in amino acid, peptide, and lipid metabolism of the host (Waters and Ley 2019). The genus Prevotellaceae UCG 004 degrades polysaccharides and produces SCFAs (Heinritz et al. 2016). Moreover, the genera Bacteroides, Alistipes, and Rikenellaceae RC9 gut group belong to Bacteroidetes. The genus Bacteroides improves ruminant metabolism by metabolizing bile acid, protein, and fat, and regulating carbohydrate metabolism. In comparison, the genus Alistipe metabolizes short-chain fatty acids. Both $\mathrm{Bac}$ teroides and Alistipe contain bile-tolerant microorganisms (David et al. 2014) and increase lipid metabolism by regulating the production of acetic acid (Yin et al. 2018). However, the genus Rikenellaceae RC9 gut group also metabolizes lipids (Zhou et al. 2018). Since both musk deer are typical ruminants, the identified dominant bacteria are critical for food digestion, nutrient absorption, and energy metabolism.

The relative abundance of genera Christensenellaceae $R 7$ group, Ruminococcus, Prevotellaceae UCG-004, and Monoglobus were significantly higher in FMD than in AMD. In contrast, genera Bacteroides, UCG-005, Rikenellaceae RC9 gut group, and Alistipes were more dominant in AMD than in FMD. Moreover, gene function annotation and prediction showed that the expression of metabolic function was higher in AMD gut microbiota than in FMD. FMD is the smallest animal in the Moschidae family, and the body size of
AMD is significantly larger than that of FMD (Wu and Wang 2006). Consequently, AMD requires higher energy and substance metabolism for growth, development, and activity than FMD. Moreover, higher gut microbial metabolism is conducive for maintaining higher energy and substance metabolism in AMD.

Furthermore, the relative abundance of opportunistic pathogens and the expression of disease-related functions were significantly higher in AMD than in FMD, suggesting that captive AMD may be at greater risk of intestinal diseases than FMD. For example, the genus Treponema is associated with dysentery, which causes severe colon inflammation. Moreover, gout patients showed an increased relative abundance of genus Erysipelatoclostridium in their intestinal tract (Shao et al. 2017). The genus Odoribacter may cause several intestinal diseases, such as colitis, necrotizing enteritis, and gastroenteritis (Meng et al. 2019). Most species in Corynebacterium are opportunistic pathogens that cause endocarditis, bacteremia, and respiratory tract, urinary tract, and various other types (Aravena-Roman et al. 2012). Besides, the genus Parasutterella can cause chronic inflammation (Peng et al. 2019). Altogether, the above potential pathogens may explain the high mortality of captive AMD.

In conclusion, this study systematically and comprehensively analyzed the differences in gut microbial structure and function between FMD and AMD using 16S rRNA gene analysis of fecal samples from 166 captive musk deer in different seasons and ages. The results showed that the alpha diversity was higher in FMD than in AMD. There were significant differences in the gut microbial composition between both musk deer. The B-diversity between adult FMD and AMD was higher than between juvenile individuals, and the value was higher in winter than in late spring. The species differences indicate that the relative abundance of the phylum Firmicutes and the genera Christensenellaceae R7 group, Ruminococcus, Prevotellaceae UCG-004, and Monoglobus were significantly higher in FMD than in AMD. In contrast, the phylum Bacteroidetes and the genera Bacteroides, UCG-005, Rikenellaceae RC9 gut group, and Alistipes were significantly higher in abundance in AMD than in FMD. The relative abundance of most opportunistic pathogens in AMD was significantly higher than in FMD. Additionally, the metabolic functions and disease-related functions of gut microbiota were significantly higher in AMD than in FMD. The combined metagenome and metabolomic results from this study are important for evaluating the artificial breeding environment and future reintroduction programs.

Author contribution FJ and TZ conceived and designed the experiments. FJ wrote the first draft of the manuscript. FJ, JZ, DL, ZC, HG, and XC contributed to sampling and laboratory work. FJ, PS, and HW 
conducted data analysis. All authors have read and approved the final manuscript.

Funding This work was financially supported by the National Natural Science Foundation of China (U20A2012); the Strategic Priority Research Program of the Chinese Academy of Sciences (XDA23060602, XDA2002030302); Qinghai Key R\&D and Transformation Program (2019-SF-150); and the Joint Grant from Chinese Academy of Sciences-People's Government of Qinghai Province on Sanjiangyuan National Park (LHZX-2020-01).

Data availability The datasets generated for this study can be found in the NCBI Sequence Read Archive under BioProject PRJNA725631 with the accession number SUB9547782 (https://dataview.ncbi.nlm. nih.gov/object/PRJNA725631? reviewer $=$ e2rcdic27nir1a7qhp8u nlk9s6).

\section{Declarations}

Ethics approval None declared.

Conflict of interest The authors declare no competing interests.

Open Access This article is licensed under a Creative Commons Attribution 4.0 International License, which permits use, sharing, adaptation, distribution and reproduction in any medium or format, as long as you give appropriate credit to the original author(s) and the source, provide a link to the Creative Commons licence, and indicate if changes were made. The images or other third party material in this article are included in the article's Creative Commons licence, unless indicated otherwise in a credit line to the material. If material is not included in the article's Creative Commons licence and your intended use is not permitted by statutory regulation or exceeds the permitted use, you will need to obtain permission directly from the copyright holder. To view a copy of this licence, visit http://creativecommons.org/licenses/by/4.0/.

\section{References}

Aguirre M, Venema K (2015) The use of fecal samples for studying human obesity. European J Epidemiol 30:1067-1069. https://doi. org/10.1007/s10654-015-0048-z

Antwis RE, Edwards KL, Unwin B, Walker SL, Shultz S (2019) Rare gut microbiota associated with breeding success, hormone metabolites and ovarian cycle phase in the critically endangered eastern black rhino. Microbiome 7:27. https://doi.org/10.1186/ s40168-019-0639-0

Aravena-Roman M, Sproer C, Siering C, Inglis T, Schumann P, Yas$\sin \mathrm{AF}$ (2012) Corynebacterium aquatimens sp. nov., a lipophilic corynebacterium isolated from blood cultures of a patient with bacteremia. Syst Appl Microbiol 35:380-384. https://doi.org/10. 1016/j.syapm.2012.06.008

Baniel A, Amato KR, Beehner JC, Bergman TJ, Mercer A, Perlman RF, Petrullo L, Reitsema L, Sams S, Lu A, Snyder-Mackler N (2021) Seasonal shifts in the gut microbiome indicate plastic responses to diet in wild geladas. Microbiome 9:26. https://doi.org/10.1186/ s40168-020-00977-9

Barelli C, Albanese D, Stumpf RM, Asangba A, Donati C, Rovero F, Hauffe, HC (2020) The gut microbiota communities of wild arboreal and ground-feeding tropical primates are affected differently by habitat disturbance. mSystems 5:e00061-20. https://doi.org/ 10.1128/mSystems.00061-20

Bolger AM, Lohse M, Usadel B (2014) Trimmomatic: a flexible trimmer for illumina sequence data. Bioinformatics 30:2114-2120. https://doi.org/10.1093/bioinformatics/btu170

Cao J, Hu YF, Liu F, Wang YA, Bi YH, Lv N, Li J, Zhu BL, Gao GF (2020) Metagenomic analysis reveals the microbiome and resistome in migratory birds. Microbiome 8:26. https://doi.org/ 10.1186/s40168-019-0781-8

Caporaso JG, Kuczynski J, Stombaugh J, Bittinger K, Bushman FD, Costello EK (2010) QIIME allows analysis of high-throughput community sequencing data. Nat Methods 7:335-336. https://doi. org/10.1038/nmeth.f.303

Chi XW, Gao HM, Wu GS, Qin W, Song PF, Wang L, Chen JR, Cai ZY, Zhang TZ (2019) Comparison of gut microbiota diversity between wild and captive bharals (Pseudois nayaur). BMC Vet Res 15:243. https://doi.org/10.1186/s12917-019-1993-7

Comizzoli P, Holt WV (2019) Breakthroughs and new horizons in reproductive biology of rare and endangered animal species. Biol Reprod 101:514-525. https://doi.org/10.1093/biolre/ioz031

Costello EK, Lauber CL, Hamady M, Fierer N, Gordon JI, Knight R (2009) Bacterial community variation in human body habitats across space and time. Science 326(1694):1697. https://doi.org/ 10.1126/science. 1177486

David LA, Maurice CF, Carmody RN, Gootenberg DB, Button JE, Wolfe BE, Ling AV, Devlin AS, Varma Y, Fischbach MA, Biddinger SB, Dutton RJ, Turnbaugh PJ (2014) Diet rapidly and reproducibly alters the human gut microbiome. Nature 505:559_ 563. https://doi.org/10.1038/nature12820

De Filippo C, Cavalieri D, Di Paola M, Ramazzotti M, Poullet JB, Massart S, Collini S, Pieraccini G, Lionetti P (2010) Impact of diet in shaping gut microbiota revealed by a comparative study in children from Europe and rural Africa. PNAS 107:14691-14696. https://doi.org/10.1073/pnas.1005963107

Dinleyici EC, Martinez-Martinez D, Kara A, Dalgic N, Metin O, Yazar AS, Guven S, Kurugol Z, Turel O, Kucukkoc M, Yasa O, Eren M, Ozen M, Marti JM, Garay CP, Vandenplas Y, Moya A (2018) Time series analysis of the microbiota of children suffering from acute infectious diarrhea and their recovery after treatment. Front Microbiol 9:1230. https://doi.org/10.3389/fmicb.2018.01230

Enjalbert F, Combes S, Zened A, Meynadier A (2017) Rumen microbiota and dietary fat: a mutual shaping. J Appl Microbiol 123:782797. https://doi.org/10.1111/jam.13501

Fan ZX, Li WJ, Jin JZ, Cui K, Yan CC, Peng CJ, Jian ZY, Bu P, Price M, Zhang XY, Shen YM, Li J, Wenhua Q, Yue BS (2018) The draft genome sequence of forest musk deer (Moschus berezovskii). Gigascience 7:1-6. https://doi.org/10.1093/gigascience/giy038

Fan PX, Nelson CD, Driver JD, Elzo MA, Penagaricano F, Jeong KC (2021) Host genetics exerts lifelong effects upon hindgut microbiota and its association with bovine growth and immunity. ISME J 15:2306-2321. https://doi.org/10.1038/s41396-021-00925-X

Fan JM, Zheng XL, Wang HY, Qi H, Jiang BM, Qiao MP, Zhou JW, $\mathrm{Bu}$ SH (2019) Analysis of genetic diversity and population structure in three forest musk deer captive populations with different origins. G3-Genes Genom Genet 9:1037-1044. https://doi.org/ $10.1534 / \mathrm{g} 3.119 .400001$

Fountain-Jones NM, Clark NJ, Kinsley AC, Carstensen M, Forrester J, Johnson TJ, Miller EA, Moore S, Wolf TM, Craft ME (2020) Microbial associations and spatial proximity predict North American moose (Alces alces) gastrointestinal community composition. J Anim Ecol 89:817-828. https://doi.org/10.1111/1365-2656. 13154

Fransen F, van Beek AA, Borghuis T, Meijer B, Hugenholtz F, Jongh CVGD, Savelkoul HF, de Jonge MI, Faas MM, Boekschoten MV, Smidt H, El Aidy S, de Vos P (2017) The impact of gut microbiota 
on gender-specific differences in immunity. Front Immunol 8:754. https://doi.org/10.3389/fimmu.2017.00754

Fung TC, Olson CA, Hsiao EY (2017) Interactions between the microbiota, immune and nervous systems in health and disease. Nat Neurosci 20:145-155. https://doi.org/10.1038/nn.4476

Gagniere J, Raisch J, Veziant J, Barnich N, Bonnet R, Buc E, Bringer MA, Pezet D, Bonnet M (2016) Gut microbiota imbalance and colorectal cancer. World J Gastroentero 22(2):501-518. https:// doi.org/10.3748/wjg.v22.i2.501

Gao H, Chi X, Qin W, Wang L, Song P, Cai Z, Zhang J, Zhang T (2019) Comparison of the gut microbiota composition between the wild and captive Tibetan wild ass (Equus kiang). J Appl Microbiol 126:1869-1878. https://doi.org/10.1111/jam.14240

Guo JZ, Li PF, Zhang K, Zhang L, Wang XL, Li L, Zhang HP (2020a) Distinct stage changes in early-life colonization and acquisition of the gut microbiota and its correlations with volatile fatty acids in goat kids. Front Microbiol 11:584742. https:// doi.org/10.3389/fmicb.2020.584742

Guo W, Ren K, Ning RH, Li CW, Zhang HM, Li DS, Xu L, Sun FH, Dai M (2020b) Fecal microbiota transplantation provides new insight into wildlife conservation. Glob Ecol Conserv 24:e01234. https://doi.org/10.1016/j.gecco.2020.e01234

Harris R (2016) Moschus chrysogaster. The IUCN red list of threatened species 2016: e.T13895A61977139. https://doi.org/10. 2305/IUCN.UK.2016-1.RLTS.T13895A61977139.en. Downloaded on 15 May 2021.

Heinritz SN, Weiss E, Eklund M, Aumiller T, Louis S, Rings A, Messner S, Camarinha-Silva A, Seifert J, Bischoff SC, Mosenthin R (2016) Intestinal microbiota and microbial metabolites are changed in a pig model fed a high-fat/low-fiber or a lowfat/high-fiber diet. PLoS ONE 11:e0154329. https://doi.org/10. 1371/journal.pone.0154329

Hu XL, Liu G, Shafer ABA, Wei YT, Zhou JT, Lin SB, Wu HB, Zhou M, Hu DF, Liu SQ (2017) Comparative analysis of the gut microbial communities in forest and alpine musk deer using high-throughput sequencing. Front Microbiol 8:572. https://doi. org/10.3389/fmicb.2017.00572

Hua Y, Cao HQ, Wang J, He FP, Jiang GS (2020) Gut microbiota and fecal metabolites in captive and wild North China leopard (Panthera pardus japonensis) by comparison using 16S rRNA gene sequencing and LC/MS-based metabolomics. BMC Vet Res 16:363. https://doi.org/10.1186/s12917-020-02583-1

Huang J, Li YZ, Li P, Yue H, Zhang XY, Li XX, Zou FD, Ming H, Moermond T, Yue BS (2013) Genetic quality of the Miyaluo captive forest musk deer (Moschus berezovskii) population as assessed by microsatellite loci. Biochem Syst Ecol 47:25-30. https://doi.org/10.1016/j.bse.2012.10.012

Ji P, Rhoads WJ, Edwards MA, Pruden A (2017) Impact of water heater temperature setting and water use frequency on the building plumbing microbiome. ISME J 11:1318-1330. https://doi. org/10.1038/ismej.2017.14

Jiang ZG, Jiang JP, Wang YZ, Zhang E, Zhang YY, Li LL, Xie F, Cai B, Cao L, Zheng GM, Dong L, Zhang ZW, Ding P, Luo ZH, Ding CQ, Ma ZJ, Tang SH, Cao WX, Li CW, Hu HJ, Ma Y, Wu Y, Wang YX, Zhou KY, Liu SY, Chen YY, Li JT, Feng ZJ, Wang Y, Wang B, Li C, Song XL, Cai L, Zang CX, Zeng Y, Meng ZB, Fang HX, Ping XG (2016) Red list of China's vertebrates. Biodiv Sci 24(5):500-551. https://doi.org/10.17520/ biods.2016076(inChinese)

Jiang F, Zhang JJ, Gao HM, Cai ZY, Zhou XW, Li SQ, Zhang TZ (2020) Musk deer (Moschus spp.) face redistribution to higher elevations and latitudes under climate change in China. Sci Total Environ 704:135335. https://doi.org/10.1016/j.scitotenv. 2019.135335

Johnson BM, Gaudreau MC, Gudi R, Brown R, Gilkeson G, Vasu C (2020) Gut microbiota differently contributes to intestinal immune phenotype and systemic autoimmune progression in female and male lupus-prone mice. J Autoimmun 108:102420. https://doi.org/ 10.1016/j.jaut.2020.102420

Knutie SA, Gotanda KM (2018) A non-invasive method to collect fecal samples from wild birds for microbiome studies. Microb Ecol 76:851-855. https://doi.org/10.1007/s00248-018-1182-4

Korach-Rechtman H, Freilich S, Gerassy-Vainberg S, Buhnik-Rosenblau K, Danin-Poleg Y, Bar H, Kashi Y (2019) Murine genetic background has a stronger impact on the composition of the gut microbiota than maternal inoculation or exposure to unlike exogenous microbiota. Appl Environ Microb 85:e0826-e919. https:// doi.org/10.1128/AEM.00826-19

Kovacs A, Ben-Jacob N, Tayem H, Halperin E, Iraqi FA, Gophna U (2011) Genotype is a stronger determinant than sex of the mouse gut microbiota. Microb Ecol 61:423-428. https://doi.org/10.1007/ s00248-010-9787-2

La Reau AJ, Suen G (2018) The Ruminococci: key symbionts of the gut ecosystem. J Microbiol 56:199-208. https://doi.org/10.1007/ s12275-018-8024-4

La Reau AJ, Meier-Kolthoff JP, Suen G (2016) Sequence-based analysis of the genus Ruminococcus resolves its phylogeny and reveals strong host association. Microb Genom 2:000099. https://doi.org/10.1099/mgen.0.000099

Lang JM, Pan C, Cantor RM, Tang WHW, Garcia-Garcia JC, Kurtz I, Hazen SL, Bergeron N, Krauss RM, Lusis AJ (2018) Impact of individual traits, saturated fat, and protein source on the gut microbiome. mBio 9: e01604-18. https://doi.org/10.1128/mBio. 01604-18

Langille MGI, Zaneveld J, Caporaso JG, McDonald D, Knights D, Reyes JA, Clemente JC, Burkepile DE, Thurber RLV, Knight R, Beiko RG, Huttenhower C (2013) Predictive functional profiling of microbial communities using 16S rRNA marker gene sequences. Nat Biotechnol 31:814-821. https://doi.org/10.1038/ nbt. 2676

Lepczynska M, Dzika E (2019) The influence of probiotic bacteria and human gut microorganisms causing opportunistic infections on Blastocystis ST3. Gut Pathog 11:6. https://doi.org/10.1186/ s13099-019-0287-8

Ley RE, Peterson DA, Gordon JI (2006) Ecological and evolutionary forces shaping microbial diversity in the human intestine. Cell 124:837-848. https://doi.org/10.1016/j.cell.2006.02.017

Li YM, Hu XL, Yang S, Zhou JT, Zhang TX, Qi L, Sun XN, Fan MY, Xu SH, Cha M, Zhang MS, Lin SB, Liu SQ, Hu DF (2017) Comparative analysis of the gut microbiota composition between captive and wild forest musk deer. Front Microbiol 8:1705. https://doi.org/10.3389/fmicb.2017.01705

Li YM, Hu XL, Yang S, Zhou JT, Qi L, Sun XN, Fan MY, Xu SH, Cha MH, Zhang MS, Lin SB, Liu SQ, Hu DF (2018) Comparison between the fecal bacterial microbiota of healthy and diarrheic captive musk deer. Front Microbiol 9:300. https://doi. org/10.3389/fmicb.2018.00300

Macke E, Callens M, De Meester L, Decaestecker E (2017) Hostgenotype dependent gut microbiota drives zooplankton tolerance to toxic cyanobacteria. Nat Commun 8:1608. https://doi. org/10.1038/s41467-017-01714-x

Magoč T, Salzberg SL (2011) Flash: fast length adjustment of short reads to improve genome assemblies. Bioinformatics 27:29572963. https://doi.org/10.1093/bioinformatics/btr507

Matthews C, Crispie F, Lewis E, Reid M, O'Toole PW, Cotter PD (2019) The rumen microbiome: a crucial consideration when optimising milk and meat production and nitrogen utilisation efficiency. Gut Microbes 10:115-132. https://doi.org/10.1080/ 19490976.2018.1505176

Matulova M, Nouaille R, Capek P, Pean M, Delort AM, Forano E (2008) NMR study of cellulose and wheat straw degradation by 
Ruminococcus albus 20. FEBS J 275:3503-3511. https://doi. org/10.1111/j.1742-4658.2008.06497.x

Meng XC, Wang YN, Yan PG, Li YH, Wang HY, Qian JM, Li JN (2019) Effect of VSL\#3 and S.Boulardii on intestinal microbiota in mice with acute colitis. Natl Med J China 99:1735-1742 (in Chinese)

Naas AE, Solden LM, Norbeck AD, Brewer H, Hagen LH, Heggenes IM, McHardy AC, Mackie RI, Pasa-Tolic L, Arntzen MO, Eijsink VGH, Koropatkin NM, Hess M, Wrighton KC, Pope PB (2018) "Candidatus Paraporphyromonas polyenzymogenes" encodes multi-modular cellulases linked to the type IX secretion system. Microbiome 6:44. https://doi.org/10.1186/ s40168-018-0421-8

National Forestry and Grassland Administration (2009) Investigation of key terrestrial wildlife resources in China. The China Forestry Publishing House, Beijing ((in Chinese))

National Forestry and Grassland Administration (2017) Forest musk deer was released wild for the first time in China. http://www.fores try.gov.cn/. Accessed 3 July 2017 (in Chinese).

Nicholson JK, Holmes E, Kinross J, Burcelin R, Gibson G, Jia W, Pettersson S (2012) Host-gut microbiota metabolic interactions. Science 336:1262-1267. https://doi.org/10.1126/science.1223813

Ning Y, Qi JZ, Dobbins MT, Liang X, Wang JX, Chen SY, Ma JZ, Jiang GS (2020) Comparative analysis of microbial community structure and function in the gut of wild and captive amur tiger. Front Microbiol 11:1665. https://doi.org/10.3389/fmicb.2020. 01665

O'Toole PW, Jeffery IB (2015) Gut microbiota and aging. Science 350(6265):1214-1215. https://doi.org/10.1126/science.aac8469

Oksanen J, Blanchet FG, Friendly M, Kindt R, Legendre P, Mcglinn D, Minchin PR, O'Hara RB, Simpson GL, Solymos P, Stevens MHH, Szoecs E, Wagner H (2019) vegan: community ecology package, $\mathrm{R}$ package Version 2.5-6. Available online at: https://CRAN.R-proje ct.org/package $=$ vegan

Peddada S (2017) Seasonal change in the gut. Science 357(6353):754755. https://doi.org/10.1126/science.aao2997

Peng YJ, Yan YM, Wan P, Chen D, Ding Y, Ran LW, Mi J, Lu L, Zhang ZJ, Li XY, Zeng XX, Cao YL (2019) Gut microbiota modulation and anti-inflammatory properties of anthocyanins from the fruits of Lycium ruthenicum Murray in dextran sodium sulfate-induced colitis in mice. Free Radical Bio Med 136:96-108. https://doi.org/ 10.1016/j.freeradbiomed.2019.04.005

Perry M (2016) heatmaps: flexible heatmaps for functional genomics and sequence features, R Package Version 1.11.0. Available online at: https://rdrr.io/bioc/heatmaps/

Prajapati VS, Purohit HJ, Raje DV, Parmar N, Patel AB, Jones OAH, Joshi CG (2016) The effect of a high-roughage diet on the metabolism of aromatic compounds by rumen microbes: a metagenomic study using Mehsani buffalo (Bubalus bubalis). Appl Microbiol Biot 100:1319-1331. https://doi.org/10.1007/s00253-015-7239-0

Qin JJ, Li YR, Cai ZM, Li SH, Zhu JF, Zhang F, Liang SS, Zhang WW, Guan YL, Shen DQ, Peng YQ, Zhang DY, Jie ZY, Wu WX, Qin YW, Xue WB, Li JH, Han LC, Lu DH, Wu PX, Dai YL, Sun XJ, Li ZS, Tang AF, Zhong SL, Li XP, Chen WN, Xu R, Wang MB, Feng Q, Gong MH, Yu J, Zhang YY, Zhang M, Hansen T, Sanchez G, Raes J, Falony G, Okuda S, Almeida M, LeChatelier E, Renault P, Pons N, Batto JM, Zhang ZX, Chen H, Yang RF, Zheng WM, Li SG, Yang HM, Wang J, Ehrlich SD, Nielsen R, Pedersen O, Kristiansen K, Wang J (2012) A metagenome-wide association study of gut microbiota in type 2 diabetes. Nature 490(7418):55-60. https://doi.org/10.1038/nature11450

Rounge TB, Meisal R, Nordby JI, Ambur OH, de Lange T, Hoff G (2018) Evaluating gut microbiota profiles from archived fecal samples. BMC Gastroenterol 18:171. https://doi.org/10.1186/ s12876-018-0896-6
Sasaki H, Kawamura K, Kawamura T, Odamaki T, Katsumata N, Xiao JZ, Suzuki N, Tanaka M (2019) Distinctive subpopulations of the intestinal microbiota are present in women with unexplained chronic anovulation. Reprod Biomed Online 38:570-578. https:// doi.org/10.1016/j.rbmo.2018.12.026

Sassone-Corsi M, Nuccio SP, Liu H, Hernandez D, Vu CT, Takahashi AA, Edwards RA, Raffatellu M (2016) Microcins mediate competition among Enterobacteriaceae in the inflamed gut. Nature 540:280-283. https://doi.org/10.1038/nature20557

Shanahan F (2010) Probiotics in perspective. Gastroenterology 139:1808-1812. https://doi.org/10.1053/j.gastro.2010.10.025

Shao TJ, Shao L, Li HC, Xie ZJ, He ZX, Wen CP (2017) Combined signature of the fecal microbiome and metabolome in patients with gout. Front Microbiol 8:268. https://doi.org/10.3389/fmicb. 2017.00268

Shor EK, Brown SP, Freeman DA (2020) A novel role for the pineal gland: regulating seasonal shifts in the gut microbiota of Siberian hamsters. J Pineal Res 69:e12696. https://doi.org/10. 1111/jpi.12696

Silla AJ, Byrne PG (2019) The role of reproductive technologies in amphibian conservation breeding programs. Annu Rev Anim Biosci 7:499-519. https://doi.org/10.1146/annur ev-animal-020518-115056

Sun XN, Cai RB, Jin XL, Shafer ABA, Hu XL, Yang S, Li YM, Qi L, Liu SQ, Hu DF (2018) Blood transcriptomics of captive forest musk deer (Moschus berezovskii) and possible associations with the immune response to abscesses. Sci Rep 8:599. https:// doi.org/10.1038/s41598-017-18534-0

Thitaram C, Brown JL (2018) Monitoring and controlling ovarian activity in elephants. Theriogenology 109:42-47. https://doi. org/10.1016/j.theriogenology.2017.12.009

Tong Q, Cui LY, Hu ZF, Du XP, Abid HM, Wang HB (2020) Environmental and host factors shaping the gut microbiota diversity of brown frog Rana dybowskii. Sci Total Environ 741:140142. https://doi.org/10.1016/j.scitotenv.2020.140142

Torres-Fuentes C, Schellekens H, Dinan TG, Cryan JF (2017) The microbiota-gut-brain axis in obesity. Lancet Gastroenterol 2:747-756. https://doi.org/10.1016/S2468-1253(17)30147-4

Tremaroli V, Backhed F (2012) Functional interactions between the gut microbiota and host metabolism. Nature 489:242-249. https://doi.org/10.1038/nature11552

Turnbaugh PJ, Ley RE, Mahowald MA, Magrini V, Mardis ER, Gordon JI (2006) An obesity-associated gut microbiome with increased capacity for energy harvest. Nature 444:1027-1031. https://doi.org/10.1038/nature05414

Valles-Colomer M, Falony G, Darzi Y, Tigchelaar EF, Wang J, Tito RY, Schiweck C, Kurilshikov A, Joossens M, Wijmenga C, Claes S, Van Oudenhove L, Zhernakova A, Vieira-Silva S, Raes J (2019) The neuroactive potential of the human gut microbiota in quality of life and depression. Nat Microbiol 4:623-632. https://doi.org/10.1038/s41564-018-0337-x

Wang Q, Garrity GM, Tiedje JM, Cole JR (2007) Naïve Bayesian classifier for rapid assignment of rRNA sequences into the new bacterial taxonomy. Appl Environ Microbiol 76:5261-5267. https://doi.org/10.1128/AEM.00062-07

Wang YH, Liu SQ, Yang S, Zhang TX, Wei YT, Zhou JT, Hu DF, Li LH (2016) Determination of ovarian cyclicity and pregnancy using fecal progesterone in forest musk deer (Moschus berezovskii). Anim Reprod Sci 170:1-9. https://doi.org/10.1016/j.anire prosci.2016.03.002

Wang YJ, Zhang H, Zhu L, Xu YL, Liu N, Sun XM, Hu LP, Huang H, Wei K, Zhu RL (2018) Dynamic distribution of gut microbiota in goats at different ages and health states. Front Microbiol 9:2509. https://doi.org/10.3389/fmicb.2018.02509

Wang JH, Shin NR, Lim SK, Im U, Song EJ, Nam YD, Kim H (2019) Diet control more intensively disturbs gut microbiota 
than genetic background in wild type and ob/ob mice. Front Microbiol 10:1292. https://doi.org/10.3389/fmicb.2019.01292

Wang Y, Harris R (2015) Moschus berezovskii. The IUCN red list of threatened species 2015: e.T13894A103431781. https://doi. org/10.2305/IUCN.UK.2015-4.RLTS.T13894A61976926.en. Downloaded on 15 May 2021.

Wasimuddin MS, Melzheimer J, Thalwitzer S, Heinrich S, Wachter B, Sommer S (2017) Gut microbiomes of free-ranging and captive Namibian cheetahs: diversity, putative functions and occurrence of potential pathogens. Mol Ecol 26:5515-5527. https:// doi.org/10.1111/mec.14278

Waters JL, Ley RE (2019) The human gut bacteria Christensenellaceae are widespread, heritable, and associated with health. BMC Biol 17:83. https://doi.org/10.1186/s12915-019-0699-4

Wei FW, Wu Q, Hu YB, Huang GP, Nie YG, Yan L (2019) Conservation metagenomics: a new branch of conservation biology. Sci China Life Sci 62:168-178. https://doi.org/10.1007/ s11427-018-9423-3

Willard ST, Hughes DM, Bringans M, Sasser RG, White DR, Jaques JT, Godfrey RW, Welsh TH, Randel RD (1996) Artificial insemination, hybridization and pregnancy detection in sika deer (Cervus nippon). Theriogenology 46:779-789. https://doi.org/10.1016/ S0093-691X(96)00236-1

Wu JY, Wang W (2006) The musk deer of China. The China Forestry Publishing House, Beijing ((in Chinese))

Wu GD, Chen J, Hoffmann C, Bittinger K, Chen YY, Keilbaugh SA, Bewtra M, Knights D, Walters WA, Knight R, Sinha R, Gilroy E, Gupta K, Baldassano R, Nessel L, Li HZ, Bushman FD, Lewis JD (2011) Linking long-term dietary patterns with gut microbial enterotypes. Science 334:105-108. https://doi.org/10.1126/scien ce. 1208344

Wu SJ, Bekhit AEA, Wu QP, Chen MF, Liao XY, Wang J, Ding Y (2021) Bioactive peptides and gut microbiota: candidates for a novel strategy for reduction and control of neurodegenerative diseases. Trends Food Sci Tech 108:164-176. https://doi.org/10. 1016/j.tifs.2020.12.019

Xiong XY, Loo SL, Zhang L, Tanaka MM (2021) Modelling the effect of birth and feeding modes on the development of human gut microbiota. P Roy Soc B-Biol Sci 288:20201810. https://doi.org/ 10.1098/rspb.2020.1810

Xu ZC, Cao LX, Liu J, Tan HM, Deng ZJ (2018) Evaluation of the diversity of probiotic Bacillus, Clostridium, and Bifidobacterium using the Illumina-based sequencing method. Probiotics Antimicro 10:748-754. https://doi.org/10.1007/s12602-017-9337-z

Yin J, Li YY, Han H, Chen S, Gao J, Liu G, Wu X, Deng JP, Yu QF, Huang XG, Fang RJ, Li TJ, Reiter RJ, Zhang D, Zhu CR, Zhu GQ, Ren WK, Yin YL (2018) Melatonin reprogramming of gut microbiota improves lipid dysmetabolism in high-fat diet-fed mice. J Pineal Res 65:e12524. https://doi.org/10.1111/jpi.12524

Zhao YY, Qing J (2021) Roles of the polyphenol-gut microbiota interaction in alleviating colitis and preventing colitis-associated colorectal cancer. Adv Nutr 12:546-565. https://doi.org/10.1093/ advances/nmaa104

Zhao KL, Liu Y, Zhang XY, Palahati P, Wang HN, Yue BS (2011) Detection and characterization of antibiotic-resistance genes in Arcanobacterium pyogenes strains from abscesses of forest musk deer. J Med Microbiol 60:1820-1826. https://doi.org/10.1099/ jmm.0.033332-0

Zhao GJ, Ma TY, Tang WJ, Li DY, Mishra SK, Xu ZX, Wang QL, Jie $\mathrm{H}$ (2019a) Gut microbiome of Chinese forest musk deer examined across gender and age. Biomed Res Int 2019:9291216. https://doi. org/10.1155/2019/9291216

Zhao HA, Cheng N, Zhou WQ, Chen SN, Wang Q, Gao H, Xue XF, Wu LM, Cao W (2019b) Honey polyphenols ameliorate DSSinduced ulcerative colitis via modulating gut microbiota in rats. Mol Nutr Food Res 63:23. https://doi.org/10.1002/mnfr.20190 0638

Zhou LY, Xiao XH, Zhang Q, Zheng J, Li M, Yu M, Wang XJ, Deng MQ, Zhai X, Li RR (2018) Improved glucose and lipid metabolism in the early life of female offspring by maternal dietary genistein is associated with alterations in the gut microbiota. Front Endocrinol 9:516. https://doi.org/10.3389/fendo.2018.00516

Zhou C, Zhang WB, Wen QC, Bu P, Gao J, Wang GN, Jin JZ, Song YJ, Sun XH, Zhang YF, Jiang X, Yu HR, Peng CJ, Shen YM, Price MG, Li J, Zhang XY, Fan ZX, Yue BS (2019) Comparative genomics reveals the genetic mechanisms of musk secretion and adaptive immunity in Chinese forest musk deer. Genome Biol Evol 11:1019-1032. https://doi.org/10.1093/gbe/evz055

Publisher's note Springer Nature remains neutral with regard to jurisdictional claims in published maps and institutional affiliations. 